Canadian Journal of Fisheries and Aquatic Sciences Journal canadien des sciences halieutiques et aquatiques

\title{
Evaluating benefits of stocking on sockeye recovery projections in a nutrient-enhanced mixed life history population
}

\begin{tabular}{|r|l|}
\hline Journal: & Canadian Journal of Fisheries and Aquatic Sciences \\
\hline Manuscript ID & cjfas-2017-0438.R1 \\
\hline Manuscript Type: & Article \\
\hline Date Submitted by the Author: & 02-Mar-2018 \\
\hline $\begin{array}{r}\text { Complete List of Authors: } \\
\text { Is the invited manuscript for } \\
\text { consideration in a Special } \\
\text { Issue? : }\end{array}$ & $\begin{array}{l}\text { Nan Poorten, Brett; BC Ministry of Environment; University of British } \\
\text { Helumbia Shander School of Business, Institute for the Oceans and Fisheries } \\
\text { Hebertish Columbia Ministry of Environment }\end{array}$ \\
\hline Keyword: & $\begin{array}{l}\text { Sockeye, Kokanee, Density-dependent, Hatchery supplementation, } \\
\text { heritability }\end{array}$ \\
\hline & \multicolumn{2}{|c}{} \\
\hline
\end{tabular}

\section{SCHOLARONE


$3 \quad$ Evaluating benefits of stocking on sockeye recovery projections

British Columbia Ministry of Environment and Climate Change Strategy, 2202 Main

32 Email: Brett.vanPoorten@gov.bc.ca

33 Phone: 604-222-6761 


\section{Abstract}

35 Dam construction often blocks migration of anadromous sockeye salmon

36 (Oncorhynchus nerka), resulting in a residualized population that is often managed

37 as landlocked kokanee. Anadromy resumes when a reconnection to the ocean is

38 established, however there may be selective pressure acting on threshold trait(s)

39 affecting smolt timing and probability. While there may be interest in predicting

40 persistence of anadromous and residual sockeye forms, this is difficult because the

41 heritability of smolting in these populations is poorly known. We develop a fully

42 density-dependent age-structured model to project abundances for both

43 anadromous and resident sockeye. The model considers trophic interactions due to

44 nutrient variation and the density dependent consequences for smolting and adult

45 returns. Moreover, it asks how each life history type will persist if a hatchery were

46 used to promote anadromous sockeye through artificial selection. We show

47 hatchery supplementation is unlikely to significantly impact anadromous or

48 resident sockeye, although there is substantial prediction uncertainty suggesting in

49 projections. Our study suggests that providing passage for previous land-locked

50 anadromous populations will lead to the return of anadromous fish in the short-

51 term, but long-term prospects are far from certain. 


\section{Introduction}

53 Dams and reservoirs are an important component of the landscape and while they

54 serve an important socio-economic function, they also pose a threat to ecological

55 integrity of the watershed (Freeman et al. 2003; Liermann et al. 2012). Dams and

56 reservoirs disrupt littoral habitat and productivity, alter hydrodynamic processes,

57 alter reservoir nutrient dynamics and complicate or remove connectivity within the

58 watershed (Friedl and Wüest 2002; Hall et al. 2011). The loss of connectivity is

59 especially important in systems that have traditionally supported anadromous fish

60 species, which annually transport large quantities of marine-derived nutrients to

61 support freshwater and surrounding terrestrial ecosystems (Schindler et al. 2005;

62 Scheuerell et al. 2007; Hall et al. 2012). Additionally, the impact of dams to the

63 cultural identity of indigenous communities is substantial as members of First

64 Nations who were traditionally connected to the fish and flowing water must look

65 elsewhere to satisfy this cultural and spiritual loss (Baxter 1977; Gregory and

66 Trousdale 2009). Restoration of fish passage is often technically feasible but can

67 often be expensive and decisions on whether and where to invest in passage must

68 appropriately weigh environmental, economic, social and cultural values.

69 Managing fish populations usually involves taking actions that directly or indirectly

70 affect the numbers or size of animals in the system. This can occur either due to

71 stocking, changes in fisheries management, which results in selective harvest of fish,

72 or due to enhancement of stocks or habitat (Walters and Martell 2004). However,

73 the implications for size structure and abundance are not independent (He et al. 
74 2015). Density dependent processes mean that changes in the abundance or size-

75 structure of the population result in changes in the food resources available per

76 individual, which in turn result in growth or survival implications (Lorenzen 2008).

77 On longer time scales, changes in size at age of mature individuals could result in

78 more or larger eggs produced per female, which affects density dependent survival

79 of resulting larvae in the next generation (Beverton and Holt 1957). Moreover, these

80 simple changes can be propagated through the food web through competitors,

81 predators and prey. The outcomes of any management decision can be complex and

82 counterintuitive (Hilborn and Walters 1992).

83 Augmenting fish populations with hatchery-reared, wild-stock fish is a frequently

84 used tactic in recovering low abundance populations. The basic idea is to improve

85 survival of young fish and augment abundance, but the detrimental effects of

86 hatcheries are often overlooked (Levin et al. 2001; Araki and Schmid 2010).

87 Negative consequences of stocking include increased competition with wild-

88 spawned fish, inbreeding depression, introgression and disease transfer, among

89 others (Fleming and Gross 1993; Reisenbichler and Rubin 1999; Weber and Fausch

90 2003; Araki et al. 2007; Araki and Schmid 2010). Many of these impacts are often

91 not observed in the hatchery; persistent differences between wild and hatchery fish

92 are often only evident by their performance following release in the wild (Araki et

93 al. 2008; Thrower and Hard 2009). Among anadromous species like Pacific salmon

94 (Oncorhynchus spp.), the goal of stocking is often to improve abundance of adults

95 once stocked fish smolt to the ocean, grow and return, but impacts of increased

96 densities of pre-smolting juveniles (i.e. rearing juveniles in the donor stream or 
97 lake) on the remainder of the freshwater ecosystem are often overlooked. This is

98 particularly poignant given uncertain density dependent responses in growth and

99 recruitment.

100 Sockeye salmon (O. nerka) have a broad suite of life history types due to a

101 combination of phenotypic and genotypic differences among populations and

102 individuals. Anadromous sockeye salmon rear in freshwater for one to three years

103 prior to smolting, migrate to the ocean and remain there for one to three years

104 before returning to freshwater to spawn and die, typically between ages 3-5. Some

105 sockeye, termed residents, may delay smolting or mature early without migrating to

106 the ocean (this predominantly occurs in males). Early maturing resident sockeye

107 males interbreed with anadromous sockeye by sneaking fertilization, but are

108 morphologically distinct in that they are much smaller and do not attain the typical

109 red colouration at spawning because they are inefficient at utilizing the lower

110 concentration of carotenoids in a freshwater diet (Craig and Foote 2001). Finally,

111 there are kokanee salmon, the freshwater form of $O$. nerka, which do not smolt and

112 may live sympatrically with sockeye (Taylor et al. 1996). Kokanee live for 3-5 years

113 in freshwater before spawning. Kokanee are thought to maintain genetic isolation

114 from sockeye due to differences in spawning habitat and size: while they have re-

115 evolved the ability to turn red at maturity, they are much smaller (Wood and Foote

116 1996; Craig and Foote 2001; Dodson et al. 2013).

117 Among resident and anadromous sockeye, the choice to smolt is thought to be a

118 function of a threshold trait(s) which initiates physiological changes to the body 
119 once certain conditions are met (Dodson et al. 2013), however, when anadromy is

120 blocked, sockeye may all become residents, as anadromy is not obligatory for their

121 life history (Ricker 1959). Interestingly, even kokanee populations that have been

122 isolated for thousands of years are capable of smolting and surviving in the marine

123 environment before returning to their native rivers, albeit with lower marine

124 survival than their anadromous sockeye counterparts (reviewed in Godbout et al.

125 2011). Godbout et al. (2011) reported the return of anadromy in a previously

126 isolated $O$. nerka population after passage was allowed after nearly 90 years. This

127 population is a deep-water spawner, so neither resident nor anadromous

128 individuals develop red colouration, calling into question whether these are true

129 sockeye or kokanee. Although elders of the Katzie First Nation tell stories of red

130 sockeye being caught in the upper Alouette River (above what is now the Alouette

131 Reservoir; Diamond 1955), this phenotype no longer exists. Interestingly, only a low

132 proportion of this population smolts each year, calling into question the heritability

133 and selective pressure of smolting. While several First Nations and stakeholders

134 wish to see strong annual sockeye returns to the reservoir each year, the decision to

135 invest in permanent fish passage (e.g. a fish ladder) will partially depend on

136 heritability of smolting and in turn, projected sockeye returns.

137 This study examines the density dependent consequences of stocking in a reservoir

138 with a mixed anadromous-resident sockeye population. We use existing data to

139 estimate various key population parameters, including density dependent growth

140 and survival rates. We project anadromous sockeye returns and abundance of

141 resident sockeye given the full range of uncertainty in all parameters as well as 
142 heritability of smolting. Here, heritability of smolting is used as a surrogate for

143 heritability on liability traits, which are a component of complex and relatively

144 uncertain threshold traits leading to alternative migratory tactics (Dodson et al.

145 2013). The model will be used to provide an evaluation of the value of stocking to

146 promote smolting and provide medium-term (25-year) projections for recovery of

147 the anadromous life history phenotype.

\section{Methods}

\section{Study System}

150 This study centers on the sockeye population rearing in Alouette Reservoir (49

$15117^{\prime} \mathrm{N}, 122^{\circ} 29^{\prime} \mathrm{W}$ ), in southwestern British Columbia (BC). This population exhibits

152 both freshwater resident and anadromous phenotypes. To underline ambiguity in

153 true origins of the population, we refer to all O. nerka in the population as 'nerkids'.

154 Alouette Lake Reservoir is a medium-sized reservoir (1666 ha at full-pool)

155 approximately $50 \mathrm{~km}$ west of Vancouver, Canada. The reservoir is $17 \mathrm{~km}$ long,

156 consisting of two basins separated by a shallow isthmus. The lake is home to

157 numerous cool- and cold-water species, and supports a recreational fishery on

158 rainbow trout (O. mykiss), cutthroat trout (O. clarkii), bull trout (Salvelinus

159 confluentus) and resident nerkids, although the majority of fishing effort targets

160 nerkids.

161 Alouette Reservoir was created in 1928 by completion of the Alouette Dam at the

162 south end of the lake, effectively blocking access to the reservoir from the lower 
163 Alouette River. Most flow is now redirected north to a $1 \mathrm{~km}$ long tunnel linking to

164 Stave Reservoir, where stored water is used for hydroelectric power generation.

165 The remainder of water is released through a low-level outlet in the dam to the

166 Alouette River, although water can also be released over a crest gate and a free crest

167 weir when water levels exceed 125.5 masl. Completion of the dam meant a

168 cessation of anadromy for several Pacific salmon species, including sockeye salmon,

169 as there was no provision for passage at the dam. Most salmon species were

170 extirpated from the reservoir following completion of the dam with the exception of

171 sockeye, where only obligate residents remained. This also resulted in a loss of

172 annual salmon returns to the local Katzie First Nation.

173 Productivity in Alouette Reservoir is thought to have followed the typical boom-

174 and-bust nutrient cycle of reservoir formation ('cultural oligotrophication'; Stockner

175 et al. 2000) following dam construction primarily due to a disruption of natural

176 hydrology, sedimentation in the new reservoir and loss of carbon production from

177 the littoral community. Additionally, the loss of marine-derived nutrients

178 transported by anadromous salmon have also contributed to declines in

179 productivity (Larkin and Slaney 1996; Cederholm et al. 1999). Nutrient restoration

180 in Alouette Reservoir began in 1999 with the primary objective of improving the

181 recreational fishery for resident nerkids. Since that time, inorganic agricultural

182 grade fertilizer has been added weekly from approximately May to September each

183 year. 
184 The Alouette system has been carefully monitored to promote production of a food 185 web that leads to production of nerkids. Phosphorus and nitrogen levels, as well as 186 phyto- and zooplankton densities and composition were monitored bi-monthly in 187 the first four years and monthly thereafter, in an attempt to maximize edible 188 phytoplankton while minimizing the risk of plankton bloom. The amount and ratio 189 of phosphorus to nitrogen has varied over the course of the program to adjust to 190 varying annual growing conditions and adaptively determine the optimal strategy 191 aimed at promoting the growth of edible plankton and therefore fish. Gill nets are 192 used in the fall to monitor resident nerkid size structure and hydroacoustic surveys 193 have been conducted concurrent with gill net sampling to provide an index of 194 abundance. A single beam hydroacoustic survey was used from 1998 to 2001, but 195 this was switched to a split beam survey thereafter. Finally, access point creel 196 surveys have been conducted in 1996 and 2014, providing estimates of total harvest 197 from recreational anglers; there is no other fishery on the reservoir.

198 Annual spills of water over the free crest weir began in 2005 and continued annually 199 from approximately April 15 to June 15 in an effort to re-establish smolting in the 200 nerkid population. Abundance of smolting nerkids was monitored with mark 201 recapture using two rotary screw traps in the lower Alouette River. Numbers of 202 nerkid smolts emigrating from the reservoir has varied annually from 720 to 62,000 203 (Borick-Cunningham and Smith 2016) and returns have varied annually from 0 to 204115 (Mathews et al. 2016). Returning adult nerkids have been transported to the 205 reservoir through a trap and truck system. Genetic comparisons of smolting and 206 resident nerkids has shown these two phenotypes to be considered the same 
207 population and not genetically distinct. Examination of the next generation do not 208 conclusively demonstrate intermixing of the two phenotypes (Godbout et al. 2010).

209 Re-anadromization of sockeye was originally seen as a great success for members of 210 the Katzie First Nation and local stakeholders, but the lack of improvement in the

211 annual number of smolts and the low mean marine survival $(<1 \%)$ has been

212 disappointing and led to calls by the Katzie people and local stakeholders for further 213 action to be taken.

214 To further promote smolting in Alouette nerkids, stakeholders are proposing 215 hatchery intervention. The annual supplemental stocking of nerkid fry is proposed

216 to occur over the short-term (two generations) using returning adult Alouette

217 ocean-run nerkids as parental stock. The expectation is that annual stocking of fry

218 derived from anadromous nerkids may artificially select for smolting, with the

219 objective of increasing the proportion of nerkids that smolt. Before investing

220 significant time and money on a stocking program it is important to evaluate the

221 potential success and effects of the program to resident and anadromous nerkids. At

222 present, the density dependent impacts of additional age-0 fry on the growth and

223 abundance of resident nerkids and the resultant fishery are unknown. Likewise,

224 with no prior information on the heritability of smolting and the potential outcome

225 of artificially selecting for smolting, it is difficult to predict how anadromous nerkid 226 returns will continue over time. 


\section{Model Development}

228 A two-phenotype nerkid model was developed to predict the strength of density

229 dependent processes and evaluate the potential outcomes that stocking and changes

230 in the probability of smolting may have on both the anadromous phenotype and the

231 freshwater recreational fishery. Derivation of Beverton-Holt recruitment

232 parameters and state dynamics model are described in Table 1 and parameters of

233 the models are listed in Table 2. The state-dynamics model is conditioned on smolt

234 estimates from the downstream smolt mark-recapture program (Mathews et al.

235 2016), returning smolted nerkid count data from the trap and truck program below

236 the Alouette dam (Borick-Cunningham and Smith 2016) and zooplankton densities

237 (Hebert et al. 2015) from the nutrient restoration program. The model is fit to

238 hydroacoustic, gill net and fishery data collected as part of the nutrient restoration

239 program to parameterize the demography of the nerkid population. The fitted

240 model was then used to make projections of both phenotypes for 25 years

241 considering uncertainty in the heritability of smolting.

242 A key component of this model is the stock-recruitment function, which is driven by

243 density dependent compensation and carrying capacity in juvenile mortality as

244 conditions change in the reservoir (Eqs. T1.3-T1.6). This model is derived from

245 arguments in Walters and Korman (1999) and fully described in van Poorten et al.

246 (in press). In it, the maximum survival rate, $\alpha$, is a function of a base mortality and a

247 food-dependent mortality rate, causing maximum juvenile survival to increase in

248 years of abundant food supply. The carrying capacity parameter, $\beta$, is also 
249 influenced by food density, with maximum recruitment increasing as a quadratic 250 function of food density.

251 The model includes a combination of parameters that are estimated (T1.1) and

252 assumed constant (T1.2). All indices, parameters and variables are described in

253 Table 2. Recruitment from eggs to age-1 is divided into two stanzas (Moussalli and

254 Hilborn 1986): one predicts the number of fry (age-0.5; T1.3-T1.4) and the second

255 predicts the number of yearlings (age-1; T1.5-T1.6). In both functions, recruitment

256 is limited by zooplankton availability and competition among the recruiting cohort

257 using functions suggested in Walters and Korman (1999) and van Poorten et al. (in

258 press). Recruitment to age- 0.5 fry is multiplied by a lognormally distributed process

259 error term. Initial growth is assumed to have been constant resulting in length-at-

260 age following a standard von Bertalanffy function (T1.7). Numbers at age are

261 predicted for two annual time periods: one in the autumn to correspond with timing

262 of smolting, which is initialized using estimated abundances $\left(N_{t, a} ; \mathrm{T} 1.8\right)$ and one the

263 following spring $\left(N_{(s p) t, a} ;\right.$ T1.9) to correspond to sampling dates. Consumption each

264 year is assumed to vary in response to available zooplankton and competition

265 among nerkids, assuming all size-classes feed on the same zooplankton resource.

266 This results in asymptotic size varying over time, while metabolic rate remaining

267 constant (Walters and Post 1993; van Poorten and Walters 2016; T1.10), resulting

268 in size-at-age varying each year (T1.11). Vulnerability to harvest is assumed to be a

269 logistic function of length (T1.12). The fishery is assumed to occur primarily in

270 summer, so total mortality during summer is half of annual natural mortality and all

271 of size-adjusted fishing mortality (T1.13). Nerkids spawn in autumn and hatch in 
272 spring, therefore, number of fry in fall is calculated based on egg abundance the

273 previous year using the first recruitment stanza calculation adjusted with lognormal

274 process error (T1.14). Yearlings the following spring are calculated based on

275 predicted fall fry abundance and the second recruitment stanza calculation (T1.15).

276 In subsequent years, fall abundance of nerkids in the reservoir is reduced as some

277 fish smolt out of the system in early spring. Egg production the following year is

278 based on size-based fecundity of age-3 and 4 resident nerkids (T1.16; McGurk,

279 2000) plus eggs contributed by returning anadromous nerkids (T1.17-T1.18).

280 Anadromous nerkid fecundity is based on a power function with length using

281 parameters from Pitt Lake sockeye (McGurk 2000). Because resident nerkids are

282 semelparous, the model assumes a fixed proportion of fish mature at age-3 $\left(m_{3}\right.$, set

283 at 0.9) and the remaining fish spawn the following year (T1.19).

284 Annual numbers of smolting fish are modelled as normally distributed random

285 variables with means and standard deviations set based on annual Peterson mark-

286 recapture estimates of abundance based on rotary screw traps set downstream of

287 the dam (Mathews et al. 2016). Trapping downstream of the dam was not conducted

288 in 2015; therefore no estimate of smolt outmigration was available for that year.

289 Smolt abundance in 2015 was set as a normally distributed random variable with

290 prior distributions of mean and standard deviation based on the empirical

291 distributions of each over the entire time series of smolt estimates for the system.

292 Model parameters (T1.1) were estimated using a state-space Bayesian approach

293 that jointly fit to observations of length-at-age, hydroacoustic estimates of 
294 abundance, and annual estimates of fishery harvest. Annual length-at-age

295 observations for individual fish captured in gill net sampling $\left(l_{t, a, i}\right)$ were assumed to

296 be normally distributed with observation error $\tau_{(l) t, a}$ (T1.21-T1.22)

297

1) $\quad l_{t, a, i} \sim \mathrm{N}\left(\hat{l}_{t, a}, \tau_{(l) t, a}\right)$

298 Log-transformed hydroacoustic abundance estimates were assumed to follow a

299 normal distribution. Annual autumn hydroacoustic estimates of abundance were

300 divided into age- 0 and age- 1 and older nerkids based on modal separation of annual

301 target strength distributions. Therefore model predictions of log-transformed

302 autumn abundance were fit separately to each age group based on abundance in

303 autumn

$304 \quad 2) \quad \log \left(N_{(H) t, 0}\right)=N\left(\log \left(N_{t, a=0}\right), \tau_{(H) 0}\right)$

$305 \quad 3) \quad \log \left(N_{(H) t, 1+}\right)=N\left(\log \left(\sum_{a=1}^{A} N_{t, a}\right), \tau_{(H) 1+}\right)$

306 where precisions for age- 0 and $1+$ age groups observation errors are described in

307 T1.23-T1.26.

308 Total fishery harvest has only been evaluated twice since 1998 in Alouette Reservoir

309 using creel surveys: once in 2002 (McCusker and Wilson 2002) and once in 2014

310 (Hebert et al. 2016). Log-transformed total annual harvest estimates were assumed

311 to be normally distributed

312

4) $\quad \log \left(C_{t}\right)=N\left(\log \left(\sum_{a=0}^{A} \hat{C}_{t, a}\right), \tau_{(C)}\right)$

313 where harvest precision in observation is directly estimated. 
314 Prior probability distributions for all estimated parameters are shown in Table 3.

315 We used JAGS 3.4.0 (Plummer 2003) to numerically approximate the posterior

316 probability distribution using Markov Chain Monte Carlo (MCMC) simulation.

317 Posterior distributions were calculated from 2,500,000 iterations after a burn-in of

$3181,000,000$ and thinned to provide a final sample of 1,000 from three separate chains.

319 Convergence could not be rejected using Gelmin-Rubin convergence diagnostics and

320 visual inspection of MCMC chains.

\section{Future projections}

322 The two-phenotype nerkid model was used to project the system 25 years into the

323 future using estimated parameters. Zooplankton densities were assumed to remain

324 constant at a level equal to the mean densities observed from 2011-2015. This is

325 consistent with the goals of the nutrient restoration program. Anadromous nerkid-

326 derived offspring are assumed to be stocked as fry directly into the reservoir for the

327 entire 25 years. All smolts leaving the system are assumed to be age- 1 for simplicity.

328 Nerkid fry descended from returning adults stocked into the reservoir are assumed

329 to smolt at a rate dictated by the narrow-sense heritability $\left(h^{2}\right)$ of smolting

330 (Morrisey et al. 2014; Table 4). The proportion of stocked fry that will smolt is given

331 in T4.1. Note that returning anadromous nerkids are selected as broodstock in the

332 hatchery, therefore the proportion of hatchery fry that smolt is related to the

333 difference between the proportion of the previous generation that smolted from

334 selected parents $(=1.0)$ and the general population $\left(=p_{(\text {smolt }) t-4)}\right.$. Resident nerkids in

335 future generations will also be influenced by the selection differential for smolting 
336 based on the difference between the proportions of resident nerkids that smolted

337 the previous generation and the relative genetic success of smolting (the proportion

338 of eggs laid that were derived from anadromous nerkids; T4.2). The number of

339 smolts each year is then a combination of hatchery and resident nerkid smolts

340 (T4.3). The number of anadromous nerkids returning two years later are given by

341 the smolts leaving the reservoir multiplied by a total marine survival rate (T4.4).

342 Projected dynamics of the age-structured model proceed as in Table 1, except

343 additional fish may be stocked into the reservoir as fry to the $0+$ population. These

344 fish then compete for resources with natural-spawned offspring, thereby reducing

345 survival to age-1 through increased density dependent competition. For ease of

346 interpretation, all smolts are assumed to be age-1.

347 Future projections of anadromous nerkid returns and the resident nerkid

348 population are dependent on two key parameters: marine survival rate and

349 heritability of smolting. Marine survival was fixed at $0.25 \%$ based on the geometric

350 mean observed marine survival rate for Alouette anadromous nerkids (Alouette

351 River Management Society 2015). We are not aware of any estimates of heritability

352 of smolting in sockeye; heritability was therefore assumed to be a uniform beta

353 distributed random variable with both shape parameters set to 1.0 (i.e. uniform

354 from 0-1). 


\section{Results}

356 Inorganic fertilizer added into Alouette Reservoir starting in 1999 accounted for a

357 substantive proportion of the total nitrogen and phosphorus in the system (Fig. 1).

358 Total nitrogen and phosphorus loading in the reservoir varied as researchers

359 refined the relative amounts of nitrogen and phosphorus to best produce edible

360 phytoplankton. This had an impact on zooplankton densities, although seasonal

361 averages varied widely across years. Increased nutrient load in the reservoir

362 resulted in marked increases in mean annual zooplankton densities, initially in all

363 cladocerans and later focused on Daphnia sp. (Fig. 1). Nerkid growth and size-at-age

364 immediately increased as a result of increased zooplankton densities (Fig. 2). Larger

365 nerkids released more eggs, resulting in a lagged increase in abundance of age-0

366 nerkids due to both increased egg abundance and increased survival of age- 0 fish.

367 Older age-classes also increased over time due to improved abundance and survival

368 of age-0 nerkids (Fig. 2). As abundance of both zooplankton and nerkids began to

369 stabilize, nerkid body size also stabilized with size-at-age slightly larger than before

370 nutrient restoration.

371 The model was able to estimate density dependent processes relating to survival

372 from egg to fry, and survival from fry to smolt. Carrying capacity for both stanzas

373 increased three-fold in the first two years following the onset of nutrient

374 restoration, declined as zooplankton densities declined and fry density increased

375 and stabilized at an intermediate level after 2008 (Fig. 3). Carrying capacities closely

376 track zooplankton density, with the strength of the zooplankton effect influenced by 
377 density of age- $0+$ or age-1, respectively. Carrying capacity for both stanzas was

378 similar, which reflects the difficulty in updating the prior prediction of $p_{1}-p_{3}$, which

379 allocate Beverton-Holt parameters across the two stanzas.

380 If the nutrient restoration program maintains zooplankton density at densities seen

381 in recent years, the model predicts resident nerkid vulnerable abundance to remain

382 approximately similar to what has been seen to date (Fig. 4). Unfortunately, median

383 anadromous nerkid returns are projected to decline over time due to low marine

384 survival. However, these projections include uncertainty in heritability, which

385 contribute variation in the annual distribution of predicted vulnerable resident and

386 anadromous nerkid returns. If heritability of smolting is actually low, anadromous

387 nerkid returns will persist over time despite lower survival in the marine

388 environment, albeit at low abundance (Fig 5; left panels). In this scenario, returning

389 fish are primarily smolts from the abundant resident nerkid phenotype, rather than

390 a persistent anadromous phenotype. If heritability is actually high, anadromous

391 nerkid returns will rapidly decline and that life history form will be lost because

392 marine survival is too low to maintain a sustainable anadromous run for this

393 population. Both scenarios show minimal influence on resident nerkid persistence

394 because of low inputs from anadromous nerkids each year (Fig 5; top panels).

395 If fry derived from anadromous nerkids are stocked into the reservoir, abundance of

396 resident nerkids vulnerable to the recreational fishery is projected to decline over

39725 years and the extent of the decline is directly related to stocking rate (Fig. 6a).

398 Note that vulnerable abundance is a function both of numbers, which decline with 
399 increased competition among fry, and size, which increases with reduced

400 competition following smolting. Once stocking rate exceeds 35,000 anadromous

401 nerkid fry, there is a 5\% probability of extirpation of the resident phenotype and

402 this probability increases with stocking. The range of projected resident nerkid

403 abundance is substantial, with $95 \%$ credible intervals ranging from a high

404 approximately 50,000 vulnerable resident nerkids at a stocking rate of 80,000

405 nerkid fry, down to complete extirpation. Mean anadromous nerkid returns 25

406 years in the future are projected to moderately increase with stocking rate, though

407 again, uncertainty around projections is substantial (Fig. 6b). For example, stocking

40850,000 anadromous nerkid fry results a 95\% probability that anadromous nerkid

409 returns in 25 years may range between 10 and over 3,300. Even at this high stocking

410 rate, there is a 50\% chance that projected returns 25 years in the future will be 161

411 anadromous nerkids or less.

\section{Discussion}

413 Marine-derived nutrients are an important subsidy to oligotrophic coastal systems.

414 This is especially so for reservoirs such as Alouette Reservoir, which are nutrient

415 deprived due to the effect of dams on within-reservoir nutrient dynamics (Scott et

416 al. 2017). Ordinarily, additional sockeye returning to the system would increase

417 natural nutrient levels and consequent prey density resulting in improvements to

418 production and carrying capacity (Cederholm et al. 1999; Naiman et al. 2002;

419 Schindler et al. 2003). However the nutrient restoration program offsets this benefit

420 because nutrient levels are managed to maximize edible phytoplankton 
421 concentrations. Additional marine derived nutrients would be largely matched by a

422 decline in added inorganic fertilizer. In fact, it would take substantial anadromous

423 nerkid returns to exceed added nutrient concentration in the system (Scott et al.

424 2017). The overall impact is that improved anadromous returns only add

425 competitors to the system without improving growing conditions. An important

426 lesson from the Alouette case study is that sockeye restoration targets should

427 carefully consider trophic interactions, especially in systems already undergoing

428 nutrient restoration.

429 Despite nearly ten years of anadromous nerkid returns, smolting rates from

430 Alouette Reservoir are often still low, either suggesting this is a kokanee population

431 with low smolting heritability or a sockeye population where conditions favour

432 residency over anadromy. This work highlights the substantial value of information

433 with respect to understanding the mechanisms and thresholds related to smolting

434 when considering restoring or enhancing anadromous sockeye stocks (Hansen et al.

435 2016). Barriers to migration are being re-examined and solutions such as dam

436 removal, trap-and-truck and fish ladders are being considered at many dams

437 throughout North America (Anderson et al. 2014). Predicting outcomes of

438 reintroductions is difficult in light of uncertainty in heritability and often only

439 includes extreme possibilities (e.g. 100\% anadromy or 100\% residency; Hansen et

440 al. 2016). We expect this work will guide future attempts to restore efforts to

441 restore anadromy using stranded nerkid phenotypes. 
442 Kokanee and sockeye populations occur sympatrically throughout their range, yet

443 these pairs are consistently genetically distinct, partially because of reproductive

444 isolation due to their sexual dimorphism (Foote et al. 1989; Taylor et al. 1996).

445 Taylor et al. (1996) suggested that although male kokanee may sneak fertilizations

446 with female sockeye (Foote and Larkin 1988), there must be substantial selective

447 pressure against kokanee-sockeye 'hybrids'. Although there is a substantial

448 polymorphism in body size between resident and anadromous nerkids in Alouette

449 Reservoir, there is no difference in colour (both are drab olive or silver),

450 presumably because of deep-water spawning (Moreira and Taylor 2015).

451 Performance of sockeye-kokanee hybrids has been shown to be inferior in salinity

452 tolerance, swimming performance, growth, and development rate (Wood and Foote

453 1990; Taylor and Foote 1991; Foote et al. 1992). Although Alouette nerkids have

454 smolted, returned and been released back into the reservoir for almost 10 years,

455 there have been no observations from genetic analysis of offspring from these

456 anadromous fish and no conclusive evidence of hybrids, although sample sizes were

457 low (Godbout et al. 2011; Alouette River Management Society 2015). The model

458 presented here assumes no intermixing, but neither does it assume Allee effects.

459 Given the low anadromous nerkid return rates, it may be that re-establishment in

460 the Alouette Reservoir may only be possible following one or more anomalously

461 good smolting or marine survival events, or through hatchery supplementation.

462 Our results show that sustained stocking is unlikely to dramatically improve

463 anadromous nerkid returns over the first 25 years, even at substantial stocking

464 rates. Sockeye salmon are particularly difficult to culture largely due to the potential 
465 for disease outbreak (Meyers et al. 1990). While stocking may be used as a tool to

466 select for anadromy if there is some heritability in smolting, selective pressure for

467 smolting will return to normal once hatchery supplementation is ceased. If

468 heritability were known to be high and marine survival even marginally improved,

469 the chance of successful restoration of anadromy may be higher, though this would

470 also likely spell the demise of the resident nerkid life history. Similar instances

471 where previously landlocked steelhead (O. mykiss) allowed to smolt revealed a low

472 prevalence of smolting due to low heritability (Thrower et al. 2004; Pearse et al.

473 2009). This highlights the need to determine heritability of smolting to evaluate the

474 benefits (in terms of sockeye returns) against costs of restoration or installation of

475 permanent fish passage.

476 Arguably the most uncertain process in any Pacific salmon life cycle model is marine

477 survival, which is essentially a catch-all for multiple, but unmeasured impacts on

478 anadromous fish. Alouette anadromous nerkids migrate outside times of major

479 commercial fishery openings (Godbout et al. 2011), so the causes of marine survival

480 variation are largely unknown. Marine survival for Alouette anadromous nerkids

481 has ranged from 0 to $1.3 \%$ since outmigration began, which is low among nearby

482 stocks (DFO 2010, 2017). If marine survival for Alouette anadromous nerkids were

483 to improve, the outcome for this phenotype would be better than the median

484 prediction from our models. This again serves to underscore the tremendous

485 uncertainty in restoration potential for this stock and the need to invest in

486 determining heritability to reduce this uncertainty. 
487 Our work clearly demonstrates high uncertainty in expected anadromous nerkid

488 returns if smolting continues. This suggests that from a purely ecological and

489 economic standpoint, investing in permanent upstream fish passage infrastructure

490 may not be prudent. However, this is one of many examples where the historic

491 construction of dams has directly affected one or more First Nations (Notzke 1994).

492 The decision to invest in anadromy should and does weigh ecological, economic,

493 social and cultural values; the cultural benefit to restoring anadromy would be

494 substantial. This work highlights not only the uncertain ecological benefit of

495 stocking anadromous nerkids into this system, but also the uncertain cultural gain.

496 Results here should reinforce how important it is to understand the factors that

497 contribute to smolting in order to contribute to a more certain and predictable

498 outcome, both for the hydro-electric utility who must invest in fish passage, but also

499 for the Katzie First Nation that has waited so long for salmon to return.

\section{Acknowledgements}

501 This work builds on substantial and sustained investments of time and money by

502 several groups. The Alouette River Sockeye Reanadromization Project is a

503 collaboration of the Katzie First Nation, Alouette River Management Society, BC

504 Ministry of Environment and Climate Change Strategy, Fisheries and Oceans Canada

505 and BC Hydro. Funding for the various programs is provided by BC Hydro, BC

506 Ministry of Environment and Climate Change Strategy and the Fish and Wildlife

507 Compensation Program. The Alouette Nutrient Restoration Program is conducted by

508 the BC Ministry of Environment, with assistance from Ministry of Justice and 
509 Attorney General - Fraser Regional Corrections Centre and BC Ministry of Forests,

510 Lands, Natural Resource Operations and Rural Development. Smolt enumeration is

511 managed by Katzie First Nation and LGL Environmental Consultants; the sockeye

512 transplant program is managed by the Alouette River Management Society and the

513 Fraser Regional Correction Center. We are indebted to all these organizations and

514 individuals for the substantial data and support that led to this work. 


\section{References}

516 Alouette River Management Society. 2015. Alouette sockeye adult enumeration:

517 Implementation year 7. Fish and Wildlife Compensation Program - Coastal.

518 Burnaby, BC.

519 Anderson, J.H., Pess, G.R., Carmichael, R.W., Ford, M.J., Cooney, T.D., Baldwin, C.M.,

520 and McClure, M.M. 2014. Planning Pacific salmon and steelhead reintroductions

521 aimed at long-term viability and recovery. North Am. J. Fish. Manag. 34: 72-93.

522 doi: $10.1080 / 02755947.2013 .847875$.

523 Araki, H., Berejikian, B.A., Ford, M.J., and Blouin, M.S. 2008. Fitness of hatchery-

524 reared salmonids in the wild. Evol. Appl. 1: 342-355.

525 Araki, H., Cooper, B., and Blouin, M.S. 2007. Genetic effects of captive breeding cause

526 a rapid, cumulative fitness decline in the wild. Science 318: 100-103.

527 Araki, H., and Schmid, C. 2010. Is hatchery stocking a help or harm? Aquaculture

528 308: S2-S11. Elsevier B.V. doi: 10.1016/j.aquaculture.2010.05.036.

529 Baxter, R.M. 1977. Environmental effects of dams and impoundments. Annu. Rev.

$530 \quad$ Ecol. Syst. 8: 255-283.

531 Beverton, R.J.H., and Holt, S.J. 1957. On the dynamics of exploited fish populations.

532 Chapman \& Hall, London.

533 Borick-Cunningham, G., and Smith, S. 2016. Alouette sockeye adult enumeration

534 project - (Bridging Year 2015). Fish and Wildlife Compensation Program - 
535 Coastal. Burnaby, BC.

536 Cederholm, C.J., Kunze, M.D., Murota, T., and Sibatani, A. 1999. Pacific salmon

537 carcasses: essential contributions of nutrients and energy for aquatic and

538 terrestrial ecosystems. Fisheries 24: 6-15.

539 Craig, J.K., and Foote, C.J. 2001. Countergradient variation and secondary sexual

540 color: phenotypic convergence promotes genetic divergence in carotenoid use

541 between sympatric anadromous and nonanadromous morphs of sockeye

542 salmon (Oncorhynchus nerka). Evolution 55: 380-391.

543 DFO. 2010. Assessment of Cultus Lake sockeye salmon in British Columbia in 2009

544 and evaluation of recent recovery activities. Canadian Science Advisory

545 Secretariat Science Advisory Report. Ottawa, ON.

546 DFO. 2017. Pre-season run size forecasts for Fraser River sockeye (Oncorhynchus

547 nerka) and pink (O. gorbuscha) salmon in 2017. Canadian Science Advisory

548 Secretariat Science Advisory Report. Ottawa, ON.

549 Diamond, J. 1955. The faith of a coast salish indian. British Columbia Provincial $550 \quad$ Museum, Victoria, B.C.

551 Dodson, J.J., Aubin-Horth, N., Theriault, V., and Paez, D.J. 2013. The evolutionary

552 ecology of alternative migratory tactics in salmonid fishes. Biol. Rev. 88: 602-

$553 \quad 625$.

554 Fleming, I.A., and Gross, M.R. 1993. Breeding success of hatchery and wild coho 555 salmon (Oncorhynchus kisutch) in competition. Ecol. Appl. 3: 230-245.

556 Foote, C.J., and Larkin, P.A. 1988. The role of male choice in the assortative mating of 

anadromous and non-anadromous sockeye salmon (Oncorhynchus nerka). $558 \quad$ Behaviour 106: 43-62.

559 Foote, C.J., Wood, C.C., Clarke, W.C., and Blackburn, J. 1992. Circannual cycle of 560 seawater adaptability in Oncorhynchus nerka: genetic differences between 561 sympatric sockeye salmon and kokanee. Can. J. Fish. Aquat. Sci. 49: 99-109.

562 Foote, C.J., Wood, C.C., and Withler, R.E. 1989. Biochemical genetic comparison of 563 sockeye salmon and kokanee, the anadromous and nonanadromous forms of 564 Oncorhynchus nerka. Can. J. Fish. Aquat. Sci. 46: 149-158.

565 Freeman, M.C., Pringle, C.M., Greathouse, E.A., and Freeman, B.J. 2003. Ecosystem-

566 level consequences of migratory faunal depletion caused by dams. In American $567 \quad$ Fisheries Society Symposium 35. pp. 255-266.

568 Friedl, G., and Wüest, A. 2002. Disrupting biogeochemical cycles - Consequences of 569 damming. Aquat. Sci. 64: 55-65.

570 Godbout, L., Wood, C.C., Withler, R., and Menard, D. 2010. Smolt parental lineage 571 assessment to evaluate successful spawn of returned 2009 Alouette sockeye 572 spawners. Fish and Wildlife Compensation Program - Coastal. Burnaby, BC.

573 Godbout, L., Wood, C.C., Withler, R.E., Latham, S., Nelson, R.J., Wetzel, L., Barnett-

574 Johnson, R., Grove, M.J., Schmitt, A.K., McKeegan, K.D., and Bradford, M. 2011.

575 Sockeye salmon (Oncorhynchus nerka) return after an absence of nearly 90

576 years: a case of reversion to anadromy. Can. J. Fish. Aquat. Sci. 68: 1590-1602.

577 doi: 10.1139/f2011-089.

578 Gregory, R., and Trousdale, W. 2009. Compensating aboriginal cultural losses: An 
alternative approach to assessing environmental damages. J. Environ. Manage.

580 90: $2469-2479$.

581 Hall, C.J., Jordaan, A., and Frisk, M.G. 2011. The historic influence of dams on

582 diadromous fish habitat with a focus on river herring and hydrologic

583 longitudinal connectivity. Landsc. Ecol. 26: 95-107.

584 Hall, C.J., Jordaan, A., and Frisk, M.G. 2012. Centuries of anadromous forage fish loss:

585 consequences for ecosystem connectivity and productivity. Bioscience 62: 723-

$586 \quad 731$.

587 Hansen, A.G., Gardner, J.R., Beauchamp, D.A., Paradis, R., and Quinn, T.P. 2016.

588 Recovery of sockeye salmon in the Elwha River, Washington, after dam

589 removal: dependence of smolt production on the resumption of anadromy by

590 landlocked kokanee. Trans. Am. Fish. Soc. 145: 1303-1317.

591 He, J.X., Bence, J.R., Madenjian, C.P., Pothoven, S.A., Dobiesz, N.E., Fielder, D.G.,

592 Johnson, J.E., Ebener, M.P., Cottrill, R.A., Mohr, L.C., and Koproski, S.R. 2015.

593 Coupling age-structured stock assessment and fish bioenergetics models: a

594 system of time-varying models for quantifying piscivory patterns during the

595 rapid trophic shift in the main basin of Lake Huron. Can. J. Fish. Aquat. Sci. 17:

$596 \quad 1-17$.

597 Hebert, A.S., Andrusak, G.F., Harris, S.L., and Weir, T. 2016. Alouette Reservoir

598 nutrient restoration program 2014-15. Ecosystems Branch, BC Ministry of

$599 \quad$ Environment. Victoria, BC

600 Hebert, A.S., Andrusak, G.F., Harris, S.L., Weir, T., and Vidmanic, L. 2015. Alouette 
reservoir nutrient restoration project: 5-year review, 2009-2013. Ecosystems Branch, BC Ministry of Environment. Victoria, BC.

603 Hilborn, R., and Walters, C.J. 1992. Quantitative fisheries stock assessment: Choice, 604 dynamics and uncertainty. Chapman and Hall, New York.

605 Larkin, G.A., and Slaney, P.A. 1996. Trends in marine-derived nutrient sources to 606 south coastal British Columbia streams: impending implications to salmonid 607 production. BC Ministry of Environment, Lands and Parks and BC Ministry of 608 Forests. Victoria, BC.

609 Levin, P.S., Zabel, R.W., and Williams, J.G. 2001. The road to extinction is paved with 610 good intentions: negative association of fish hatcheries with threatened salmon. 611 Proc. R. Soc. B Biol. Sci. 268: 1153-1158.

612 Liermann, C.R., Nilsson, C., Robertson, J., and Ng, R.Y. 2012. Implications of dam 613 obstruction for global freshwater fish diversity. Bioscience 62: 539-548.

614 Lorenzen, K. 2008. Fish population regulation beyond "stock and recruitment": the 615 role of density-dependent growth in the recruited stock. Bull. Mar. Sci. 83: 181616196.

617 Mathews, M.A., Smith, J.J., and Bocking, R.C. 2016. Evaluation of the migration 618 success of O. nerka (Kokanee / Sockeye) from the Alouette Reservoir, 2015. 619 Fish and Wildlife Compensation Program - Coastal. Burnaby, BC.

620 McCusker, M., and Wilson, G. 2002. Alouette Reservoir creel survey, April to October 621 2002. Vancouver, B.C. BC Hydro Power Supply Environmental Services. 622 Burnaby, BC. 
623 McGurk, M.D. 2000. Comparison of fecundity-length-latitude relationships between

624 nonanadromous (kokanee) and anadromous sockeye salmon (Oncorhynchus

625 nerka). Can. J. Zool. 78: 1791-1805.

626 Meyers, T.R., Thomas, J.B., Follett, J.E., and Saft, R.R. 1990. Infectious hematopoietic

627 necrosis virus: trends in prevalence and the risk management approach in

628 Alaskan sockeye salmon culture. J. Aquat. Anim. Health 2: 85-98.

629 Moreira, A.L., and Taylor, E.B. 2015. The origin and genetic divergence of " black"

$630 \quad$ kokanee , a novel reproductive ecotype of Oncorhynchus nerka. 1595: 1584-

$631 \quad 1595$.

632 Morrisey, M.B., de Villemereuil, P., Doligez, B., and Gimenez, O. 2014. Bayesian

633 approaches to the quantitative genetic analysis of natural populations. In

634 Quantitative Genetics in the Wild. Edited by A. Charmantier, D. Garant, and

635 L.E.B. Kruuk. Oxford University Press, Oxford. pp. 228-253.

636 Moussalli, E., and Hilborn, R. 1986. Optimal Stock Size and Harvest Rate in

637 Multistage Life History Models. Can. J. Fish. Aquat. Sci. 43: 135-141. doi:

$638 \quad 10.1139 / \mathrm{f} 86-014$.

639 Naiman, R.J., Bilby, R.E., Schindler, D.E., and Helfield, J.M. 2002. Pacific salmon,

640 nutrients, and the dynamics of freshwater and riparian ecosystems. Ecosystems

$641 \quad$ 5: 399-417.

642 Notzke, C. 1994. Aboriginal peoples and natural resources in Canada. Captus Press.

643 Pearse, D.E., Hayes, S.A., Bond, M.H., Hanson, C. V, Anderson, E.C., MacFarlane, R.B.,

644 and Garza, J.C. 2009. Over the falls? Rapid evolution of ecotypic differentiation 
645 in steelhead/ rainbow trout (Oncorhynchus mykiss). J. Hered. 100: 515-525.

646 Plummer, M. 2003. JAGS: A program for analysis of Bayesian graphical models using

647 Gibbs sampling. In Proceedings of the 3rd International Workshop on

648 Distributed Statistical Computing.

649 van Poorten, B.T., Arlinghaus, R., Daedlow, K., and Haertel-Borer, S.S. 2011. Social-

650 ecological interactions, management panaceas, and the future of wild fish

651 populations. Proc. Natl. Acad. Sci. 108: 12554-12559. doi:

$652 \quad 10.1073 /$ pnas.1013919108/-

653 /DCSupplemental.www.pnas.org/cgi/doi/10.1073/pnas.1013919108.

654 van Poorten, B.T., and Walters, C.J. 2016. How can bioenergetics help us predict

655 changes in fish growth patterns? Fish. Res. 180: 23-30. Elsevier B.V. doi:

$656 \quad$ 10.1016/j.fishres.2015.07.031.

657 Reisenbichler, R.R., and Rubin, S.P. 1999. Genetic changes from artificial propogation

658 of Pacific salmon affect the productivity and viability of supplemented

659 populations. ICES J. Mar. Sci. 56: 459-466.

660 Ricker, W.E. 1959. Additional observations concerning residual sockeye and

661 kokanee (Oncorhynchus nerka). J. Fish. Res. Board Canada 16: 897-902.

662 Scheuerell, M.D., Moore, J.W., Schindler, D.E., and Harvey, C.J. 2007. Varying effects of

663 anadromous sockeye salmon on the trophic ecology of two species of resident

664 salmonids in southwest Alaska. Freshw. Biol. 52: 1944-1956.

665 Schindler, D.E., Leavitt, P.R., Brock, C.S., Johnson, S.P., and Quay, P.D. 2005. Marine-

666 derived nutrients, commercial fisheries, and production of salmon and lake 

algae in Alaska. Ecology 86: 3225-3231.

668 Schindler, D.E., Scheuerell, M.D., Moore, J.W., Gende, S.M., Francis, T.B., and Palen, 669 W.J. 2003. Pacific salmon and the ecology of coastal ecosystems. Front. Ecol. $670 \quad$ Environ. 1: 31-37.

671 Scott, D.C., Harris, S.L., Hebert, A.S., and van Poorten, B.T. 2017. Nutrient dynamics in 672 a highly managed reservoir system: considering anadromous sockeye salmon 673 (Oncorhynchus nerka) and nutrient restoration. Lake Reserv. Manag. 33: 14-22.

674 Stockner, J.G., Rydin, E., and Hyenstrand, P. 2000. Cultural oligotrophication: causes 675 and consequences for fisheries resources. Fisheries 25: 7-14.

676 Taylor, E.B., and Foote, C.J. 1991. Critical swimming velocities of juvenile sockeye 677 salmon and kokanee, the anadromous and non-anadromous forms of 678 Oncorhynchus nerka (Walbaum). J. Fish Biol. 38: 407-419.

679 Taylor, E.B., Foote, C.J., and Wood, C.C. 1996. Molecular genetic evidence for parallel 680 life-history evolution within a Pacific salmon (sockeye salmon and kokanee, 681 Oncorhynchus nerka). Evolution 50: 401-416.

682 Thrower, F., Guthrie, C.I., Nielsen, J., and Joyce, J. 2004. A comparison of genetic 683 variation between an anadromous steelhead, Oncorhynchus mykiss, population 684 and seven derived populations sequestered in freshwater for 70 years. Environ. $685 \quad$ Biol. Fishes 69: 111-125.

686 Thrower, F.P., and Hard, J.J. 2009. Effects of a single event of close inbreeding on 687 growth and survival in steelhead. Conserv. Genet. 10: 1299-1307.

688 Walters, C., and Korman, J. 1999. Linking recruitment to trophic factors: revisiting 

the Beverton-Holt recruitment model from a life history and multispecies perspective. Rev. Fish Biol. Fish. 9: 187-202.

691 Walters, C., and Martell, S. 2004. Fisheries ecology and management. Princeton 692 University Press, Princeton.

693 Walters, C.J., and Post, J.R. 1993. Density-dependent growth and competitive 694 asymmetries in size-structured fish populations: A theoretical model and 695 recommendations for field experiments. Trans. Am. Fish. Soc. 122: 34-45.

696 Weber, E.D., and Fausch, K.D. 2003. Interactions between hatchery and wild 697 salmonids in streams: differences in biology and evidence for competition. Can. 698 J. Fish. Aquat. Sci. 60: 1018-1036.

699 Wood, C.C., and Foote, C.J. 1990. Genetic differences in the early development and 700 growth of sympatric sockeye salmon and kokanee (Oncorhynchus nerka), and 701 their hybrids. Can. J. Fish. Aquat. Sci. 47: 2250-2260.

702 Wood, C.C., and Foote, C.J. 1996. Evidence for symnpatric genetic divergence of 703 anadromous and nonanadromous morphs of sockeye salmon (Oncorhynchus 704 nerka). Evolution 50: 1265-1279. 


\section{Figures}

Figure 1: Total nitrogen (top panel) and phosphorus (middle panel) loads in Alouette Reservoir from 1998 to 2015, separated into natural loading and mass added through the nutrient restoration program. Bottom panel shows the associated zooplankton biomass over the same years, broken up into copepods, daphnia and other cladocerans.

Figure 2: Median (lines) and 95\% credible interval (shaded area) of predicted length-at-age (top panel) for nerkids in Alouette Reservoir from 1998-2015. Observed (circles) and predicted (lines and shaded area) abundance of age- 0 (middle panel) and age-1 to -4 nerkids (bottom panel) in the hydroacoustic surveys from 1998-2015. Hydroacoustic surveys are assumed to be non-selective for age.

Figure 3: Log-transformed carrying capacity for nerkids in Alouette Reservoir from 1998-2015 for two stanzas: (top panel) egg to fry; and (bottom panel) fry to age-1.

Figure 4: Time series of vulnerable resident nerkid abundance (top panel) and anadromous nerkid returns (bottom panel) from 1998-2040. Posterior distributions of each are characterized by median estimates (solid line) and projections (dotted line) and 95\% credible intervals (shaded area). Resident nerkid returns from 19982015 (dots) are observed data. Projections assume uniform distribution of heritability from 0 to 1 . 
Figure 5: Time series of vulnerable resident nerkid abundance (top panels) and anadromous nerkid returns (bottom panels) from 1998-2040. Posterior distributions are characterized as above. Projections assume heritability is known at either 0.2 (left panels) or 0.8 (right panels).

Figure 6: Projected abundance at year-25 of vulnerable of resident nerkids (A) and anadromous nerkid returns (B) after constant stocking at a particular rate. Solid line represents median predictions, shaded areas represent different credible intervals. 
Table 1: Statistical catch-age model of the mixed resident-anadromous nerkid system including two-stage Beverton-Holt recruitment and density-dependent growth.

\section{Parameters}

T1.1 $\theta=\left(L_{\infty, 1}, K, L_{0}, c^{(1)}, c^{(2)}, c^{(3)}, p_{1}, p_{2}, p_{3},\left\{N_{0, a}\right\}_{a=1}^{a=A}, M, F, \lambda, \tau, \xi, \psi, \chi,\left\{\varepsilon_{t}\right\}_{t=1}^{t=T}\right)$

$\mathrm{T} 1.2 \varphi=\left(a_{e}, b_{e}, L_{50(f)}, \sigma_{(f)}, m_{3}, \rho\right)$

Multi-stanza stock recruit variables

$\mathrm{T} 1.3 \quad \alpha_{(1) t}=\exp \left(-c^{(1)} p_{1}-\frac{c^{(2)} p_{2}}{z_{t}}\right)$

T1.4 $\quad \beta_{(1) t}=\frac{c^{(3)} p_{3}}{c^{(1)} p_{1} z_{t}^{2}+c^{(2)} p_{2} z_{t}}\left(1-a_{(1) t}\right)$

T1.5

$$
\alpha_{(1+) t}=\exp \left(-c^{(1)}\left(1-p_{1}\right)-\frac{c^{(2)}\left(1-p_{2}\right)}{z_{t}}\right)
$$

T1.6

$$
\beta_{(1+) t}=\frac{c^{(3)}\left(1-p_{3}\right)}{c^{(1)}\left(1-p_{1}\right) z_{t}^{2}+c^{(2)}\left(1-p_{2}\right) z_{t}}\left(1-a_{(1+) t}\right)
$$

Initial population

$\mathrm{T} 1.7 \quad \hat{l}_{t=1, a}=\left\{\begin{array}{cc}L_{0} & a=0 \\ L_{0} e^{-K a}+L_{\infty, 1}\left(1-e^{-K a}\right) & a \geq 1\end{array}\right.$

T1.8 $\widehat{N}_{t=1, a}=N_{0, a}$

$$
\widehat{N}_{(s p) t=2, a}=\left\{\begin{array}{cc}
\frac{N_{0, a} \alpha_{(1+) 1}}{1+N_{0, a} \beta_{(1+) 1}} & a=1 \\
N_{0, a-1} e^{-M / 2} & a \geq 2
\end{array}\right.
$$

State dynamics

$\mathrm{T} 1.10 \quad L_{\infty, t}=\frac{\tau+\lambda z_{t}}{1+\xi \sum_{a=0}^{A}\left(N_{t, a} L_{t-1, a}^{2}\right)}$

$\mathrm{T} 1.11$

$$
\hat{l}_{t, a}=\left\{\begin{array}{cc}
L_{0} & a=0 \\
\hat{l}_{t-1, a-1}+L_{\infty, t}\left(1-e^{-K}\right) & a \geq 1
\end{array}\right.
$$

$\mathrm{T} 1.12$

$$
v_{t, a}=\left[1+\exp \left(-\frac{\left(\hat{l}_{t, a}-L_{50(f)}\right)}{\sigma_{(f)}}\right)\right]^{-1}
$$

$$
Z_{a, t}=M / 2+v_{t, a} F
$$


$\mathrm{T} 1.14 \quad \widehat{N}_{t, a}=\left\{\begin{array}{cc}\frac{\widehat{E}_{t-1} \alpha_{(1) t}}{1+\widehat{E}_{t-1} \beta_{(1) t}} e^{\varepsilon_{t}-0.5 \sigma_{(R)}^{2}} & a=0 ; \varepsilon_{t}=N\left(0, \sigma_{(R)}\right) \\ \left(\widehat{N}_{(s p) t, a-1}-\hat{s}_{t, a-1}\right) \frac{v_{t, a} F}{Z_{a, t}} e^{-Z_{a, t}} & 1<a<A \\ \widehat{N}_{(s p) t, a-1} \frac{v_{t, a} F}{Z_{a, t}} e^{-Z_{a, t}} & a=A\end{array}\right.$

T1.15 $\widehat{N}_{(s p) t+1, a}=\left\{\begin{array}{cc}\frac{\widehat{N}_{t, a} \alpha_{(1+) t}}{1+\widehat{N}_{t, a} \beta_{(1+) t}} & a=1 \\ \widehat{N}_{t, a} e^{-(M / 2)} & 1<a<A-2 \\ \widehat{N}_{t, a}\left(1-m_{3}\right) e^{-(M / 2)} & A-1\end{array}\right.$

$\mathrm{T} 1.16 \hat{f}_{t, a}=a_{e}+\hat{l}_{t, a} \exp \left(b_{e}\right) \quad\{a=A-1, A\}$

$\mathrm{T} 1.17 \hat{E}_{(S) t}=\hat{f}_{S} \widehat{N}_{(S) t} / 2$

T1.18 $\hat{E}_{t}=\left(\hat{f}_{3} \widehat{N}_{t, 3} m_{3}+\hat{f}_{A} \widehat{N}_{t, A}\right) / 2+\hat{E}_{(S) t}$

Fishery catch-at-age observations

T1.19 $\hat{C}_{t, a}=\widehat{N}_{t, a}\left(1-e^{-v_{t, a} F_{t}}\right)$

Process and observation error

$\mathrm{T} 1.20 \quad \sigma_{(R)}=\rho \psi$

$\mathrm{T} 1.21 \quad \sigma_{(l) t, a}=\hat{l}_{t, a} c v_{l}$

$\mathrm{T} 1.22 \quad \tau_{(l) t, a}=\sigma_{(l) t, a}{ }^{-2}$

$\mathrm{T} 1.23 \quad \sigma_{(H) a=0}=(1-\rho) \psi \chi$

$\mathrm{T} 1.24 \tau_{(H) a=0}=\sigma_{(H) a=0}{ }^{-2}$

T1.25 $\sigma_{(H) a=1+}=(1-\rho) \psi(1-\chi)$

$\mathrm{T} 1.26 \tau_{(H) a=1+}=\sigma_{(H) a=1+}{ }^{-2}$ 
Table 2: Notation for the statistical catch-age models. Values of ++ indicate

estimated parameters. Parameter descriptions include units in parenthesis.

\begin{tabular}{|c|c|c|}
\hline Symbol & Value & Description \\
\hline \multicolumn{3}{|l|}{ Indices } \\
\hline$t$ & $\{1,2, \ldots \mathrm{T}\}$ & Time step ( $\mathrm{T}=15)$ \\
\hline$a$ & $\{1,2, \ldots \mathrm{A}\}$ & Age-class $(A=4)$ \\
\hline \multicolumn{3}{|c|}{ Model parameters } \\
\hline$L_{\infty, 1}$ & ++ & Asymptotic length in first year (mm) \\
\hline$K$ & ++ & von Bertalanffy metabolic parameter $\left(\mathrm{yr}^{-1}\right)$ \\
\hline$L_{0}$ & ++ & Age at age $-0(\mathrm{~mm})$ \\
\hline$c^{(1)}$ & ++ & Base mortality parameter \\
\hline$c^{(2)}$ & ++ & Mortality per time spent foraging $\left(\mathrm{N}_{\text {prey }}{ }^{-1}\right)$ \\
\hline$c^{(3)}$ & ++ & Carrying capacity parameter $\left(\right.$ fish $\left.^{-1}\right)$ \\
\hline$p_{1}, p_{2}, p_{3}$ & ++ & $\begin{array}{l}\text { Proportion of } c^{(1)}, c^{(2)}, c^{(3)} \text { attributed to first or } \\
\text { second stanza }\end{array}$ \\
\hline$N_{0, a}$ & ++ & Initial abundance at age- $a$ \\
\hline$M$ & ++ & Instantaneous natural mortality rate $\left(\mathrm{yr}^{-1}\right)$ \\
\hline$F$ & ++ & Instantaneous fishing mortality rate $\left(\mathrm{yr}^{-1}\right)$ \\
\hline$\lambda$ & ++ & $\begin{array}{l}\text { Food-dependence parameter of density-dependent } \\
\text { growth }\left(\mathrm{mm} \mathrm{N}_{\left.\text {prey }^{-1}\right)}\right.\end{array}$ \\
\hline$\tau$ & ++ & $\begin{array}{l}\text { Alternate food parameter of density-dependent } \\
\text { growth }\left(\mathrm{N}_{\text {prey }}\right)\end{array}$ \\
\hline$\xi$ & ++ & $\begin{array}{l}\text { Competition-dependence parameter of density- } \\
\text { dependent growth }\left(\mathrm{mm}^{-2}\right)\end{array}$ \\
\hline$\psi$ & ++ & Total (observation + process) error \\
\hline$\chi$ & ++ & $\begin{array}{l}\text { Proportion of acoustic observation error } \\
\text { attributed to age- } 0\end{array}$ \\
\hline$a_{e}$ & -7.151 & Egg-length multiplier (egg fl-1) \\
\hline$b_{e}$ & 2.375 & Egg-length exponent \\
\hline$L_{50(f)}$ & 225 & Length-at- $50 \%$ vulnerability to angling \\
\hline$\sigma_{(f)}$ & 20 & Angling vulnerability variance \\
\hline$m_{3}$ & 0.9 & Proportion of kokanee mature at age- 3 \\
\hline$\rho$ & 0.75 & $\begin{array}{l}\text { Proportion of total error attributed to process } \\
\text { error }\end{array}$ \\
\hline$S v_{m}$ & 0.0025 & Marine survival for sockeye from smolt to return \\
\hline \multicolumn{3}{|c|}{ Derived variables } \\
\hline$L_{\infty, t}$ & & Asymptotic length in year- $t(\mathrm{~mm})$ \\
\hline$\hat{l}_{t, a}$ & & Length-at-age in year- $t(\mathrm{~mm})$ \\
\hline$\hat{f}_{t, a}$ & & Fecundity at age in year- $t$ (eggs/female) \\
\hline$v_{t, a}$ & & Length-based vulnerability to angling in year- $t$ \\
\hline
\end{tabular}




\begin{tabular}{ll}
\hline$\alpha_{(1) t}, \alpha_{(1+) t}$ & Maximum survival to age-1 or -1+, respectively \\
$\beta_{(1) t}, \beta_{(1+) t}$ & Carrying capacity parameter to age-1 and 1+, \\
$Z_{a, t}$ & respectively (fish ${ }^{-1}$ ) \\
$\sigma_{(R)}$ & Total fishing mortality at age in year- $t$ \\
$\sigma_{(H) a=0}, \sigma_{(H) a=1+}$ & Process error in age- $0+$ recruitment \\
$\sigma_{(l) t, a}$ & Observation error in age-0 and -1+ abundance \\
$\tau_{(C)}$ & Observation error in length-at-age \\
$S_{\text {State variables }}$ & Precision in observation error for annual catch \\
$\widehat{N}_{t, a}$ & \\
$\widehat{N}_{(s p) t, a}$ & Number of age- $a$ fish in fall of year- $t$ \\
$V_{t}$ & Number of age- $a$ fish in spring of year- $t$ \\
$\hat{C}_{t, a}$ & Vulnerable abundance in year- $t$ \\
$\widehat{E}_{(S) t}$ & Catch at age in year- $t$ \\
$\widehat{E}_{t}$ & Sockeye eggs in year- $t$ \\
Observations & Total (sockeye + kokanee) eggs in year- $t$ \\
$I_{t, a}$ & \\
$C_{t, a}$ & Hydroacoustic survey index in year- $t$ for ages $a-0$ \\
$l_{t, a, i}$ & or $a=1-4$ combined \\
Management Controls & Catch of age- $a$ fish in year- $t$ in recreational fishery \\
$x_{t}$ & Length-at-age in year- $t$ for individual $i$ \\
& \\
Uncertain states & Spring age- 0 stocked fry descended from returning \\
$h^{2}$ & sockeye (fish) \\
\hline
\end{tabular}


Table 3: Prior probability density functions (PDF) and posterior predictive distributions for each estimated parameter. Prior PDFs are described as either normal $\mathrm{N}(\mu, \tau)$, uniform $\mathrm{U}($ upper, lower), beta $\mathrm{B}(\alpha, \beta)$ or gamma $\mathrm{G}($ shape, rate) distributions. Posterior distributions for parameters are reported with mean and standard deviation with upper and lower $95 \%$ credible intervals.

\begin{tabular}{lccc}
\hline Parameter & Prior PDF & Posterior PDF & 95\% Credible interval \\
\hline$L_{\infty, 1}$ & $\mathrm{U}(100,1000)$ & $287.6(7.0)$ & $274.6-300.7$ \\
$K$ & $\mathrm{U}(0,2)$ & $0.5(0.0)$ & $0.5-0.5$ \\
$L_{0}$ & $\mathrm{~N}(60,6)$ & $13.1(3.4)$ & $6.4-20.1$ \\
$c_{1}$ & $\mathrm{U}(0,10)$ & $1.8(6.4)$ & $0.7-3.3$ \\
$c_{2}$ & $\mathrm{U}(0,10)$ & $0.1(0.1)$ & $0.0-0.4$ \\
$c_{3}$ & $\mathrm{U}(0,1)$ & $0.0(0.0)$ & $0.0-0.0$ \\
$p_{1}$ & $\mathrm{~B}(2,2)$ & $0.4(0.2)$ & $0.1-0.7$ \\
$p_{2}$ & $\mathrm{~B}(2,2)$ & $0.6(0.2)$ & $0.1-0.9$ \\
$p_{3}$ & $\mathrm{~B}(2,2)$ & $0.5(0.2)$ & $0.1-0.9$ \\
$N_{0,0}$ & $\mathrm{U}(0,500,000)$ & $33,164.4(12,258.4)$ & $15,297.1-63,786.8$ \\
$N_{0,1}$ & $\mathrm{U}(0,500,000)$ & $14,062.9(9,033.4)$ & $999.7-33,249.2$ \\
$N_{0,2}$ & $\mathrm{U}(0,500,000)$ & $5,701.3(4,682.9)$ & $161.2-17,468.1$ \\
$N_{0,3}$ & $\mathrm{U}(0,500,000)$ & $6,399.4(4,677.5)$ & $313.0-17,543.3$ \\
$N_{0,4}$ & $\mathrm{U}(0,500,000)$ & $20,385.6(4.370 .1)$ & $12,060.2-29,147.2$ \\
$M$ & $\mathrm{~N}(0.6,0.6)$ & $0.9(0.1)$ & $0.6-1.1$ \\
$F$ & $\mathrm{U}(1,1)$ & $0.1(0.1)$ & $0.0-0.3$ \\
$\lambda$ & $\mathrm{U}(0,50)$ & $16.8(12.3)$ & $0.6-45.1$ \\
$\tau$ & $\mathrm{U}(0,10,000)$ & $751.1(131.4)$ & $549.3-1,019.8$ \\
$\xi$ & $\mathrm{U}(0,10)$ & $6.4(1.8)$ & $3.4-9.8$ \\
$\psi$ & $\mathrm{U}(0,10)$ & $2.8(0.3)$ & $2.3-3.4$ \\
$\chi$ & $\mathrm{B}(1,1)$ & $0.5(0.1)$ & $0.4-0.6$ \\
$c v_{l}$ & $\mathrm{~B}(1,1)$ & $0.1(0.0)$ & $0.1-0.1$ \\
$\tau_{(C)}$ & $\mathrm{G}(0.01,0.01)$ & $0.0(0.0)$ & $0.0-0.0$ \\
\hline
\end{tabular}


Table 4: Calculation of phenotypic response to selection for smolting and resulting sockeye returns in mixed kokanee-sockeye system.

Phenotypic expression

T4.1 $\quad \mathrm{Sm}^{\mathrm{H}}=p_{(\text {smolt }) t-4}+h^{2}\left(1-p_{(\text {smolt }) t-4}\right)$

T4.2 $\quad \mathrm{Sm}^{\mathrm{K}}=p_{(\text {smolt }) t-4}+h^{2}\left(\frac{E_{(S) t-2}}{E_{t-2}}-p_{(\text {smolt }) t-4}\right)$

Smolts and sockeye returns

T4.3 $\hat{s}_{t, 1}=\left(S m^{H} x_{t}+S m^{K} N_{(s p) t, 1}\right) \frac{N_{(s p) t, 1}}{N_{t-1,1}}$

T4.4 $\widehat{N}_{(S) t}=\hat{s}_{t-2,1} S v_{m}$ 

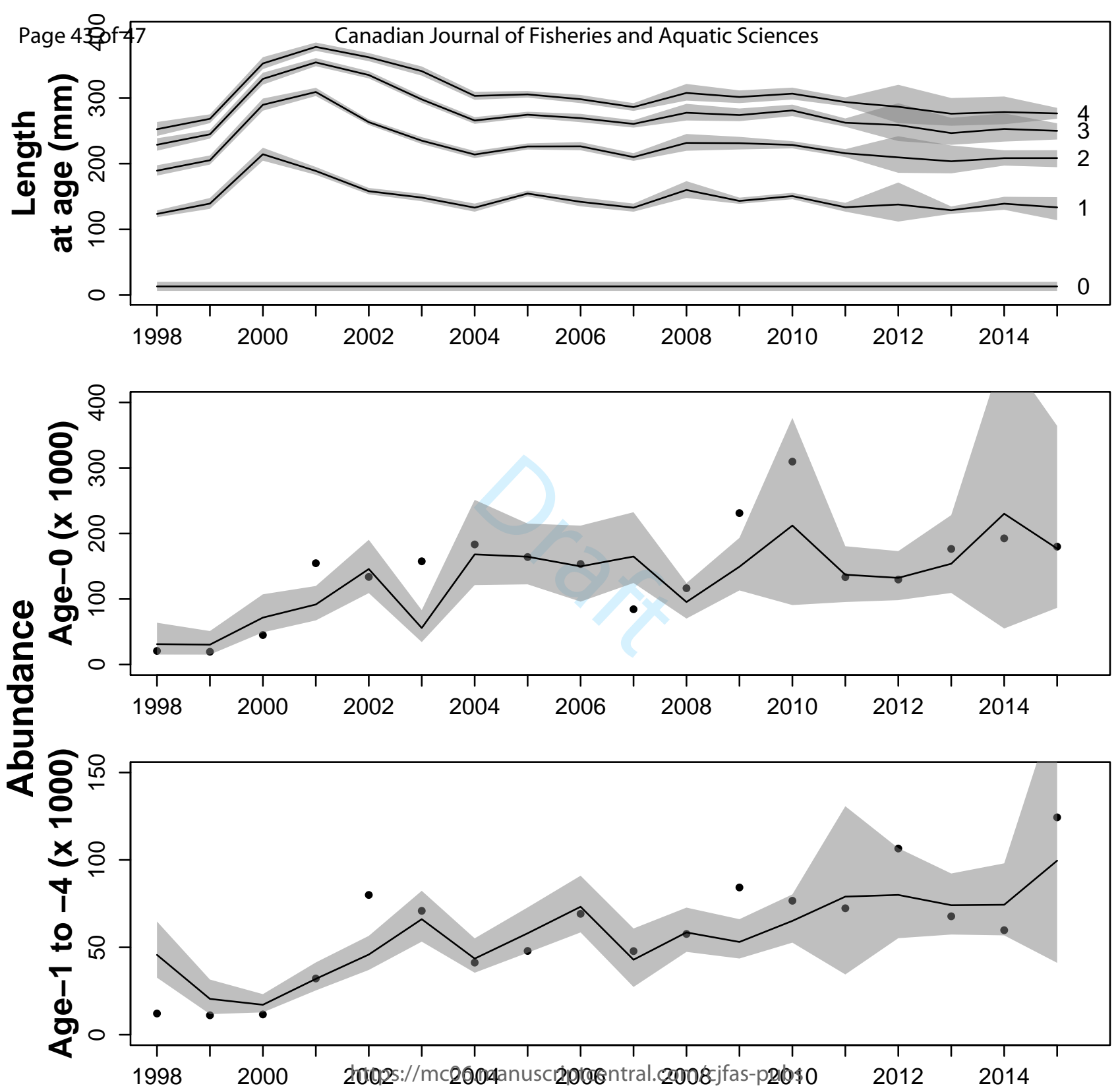


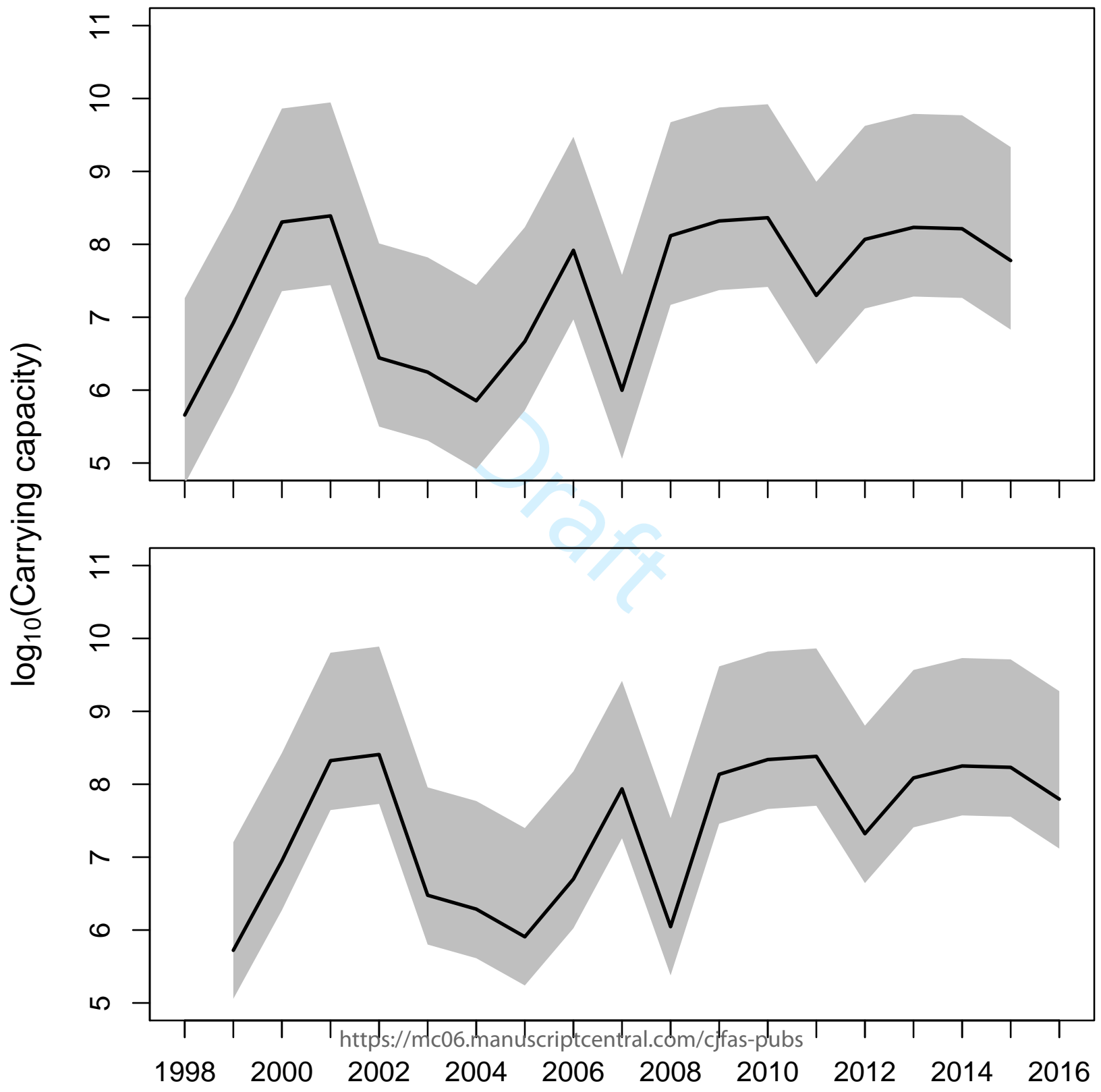




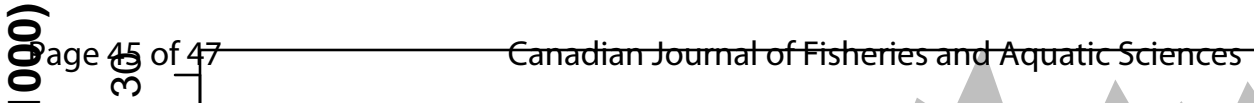
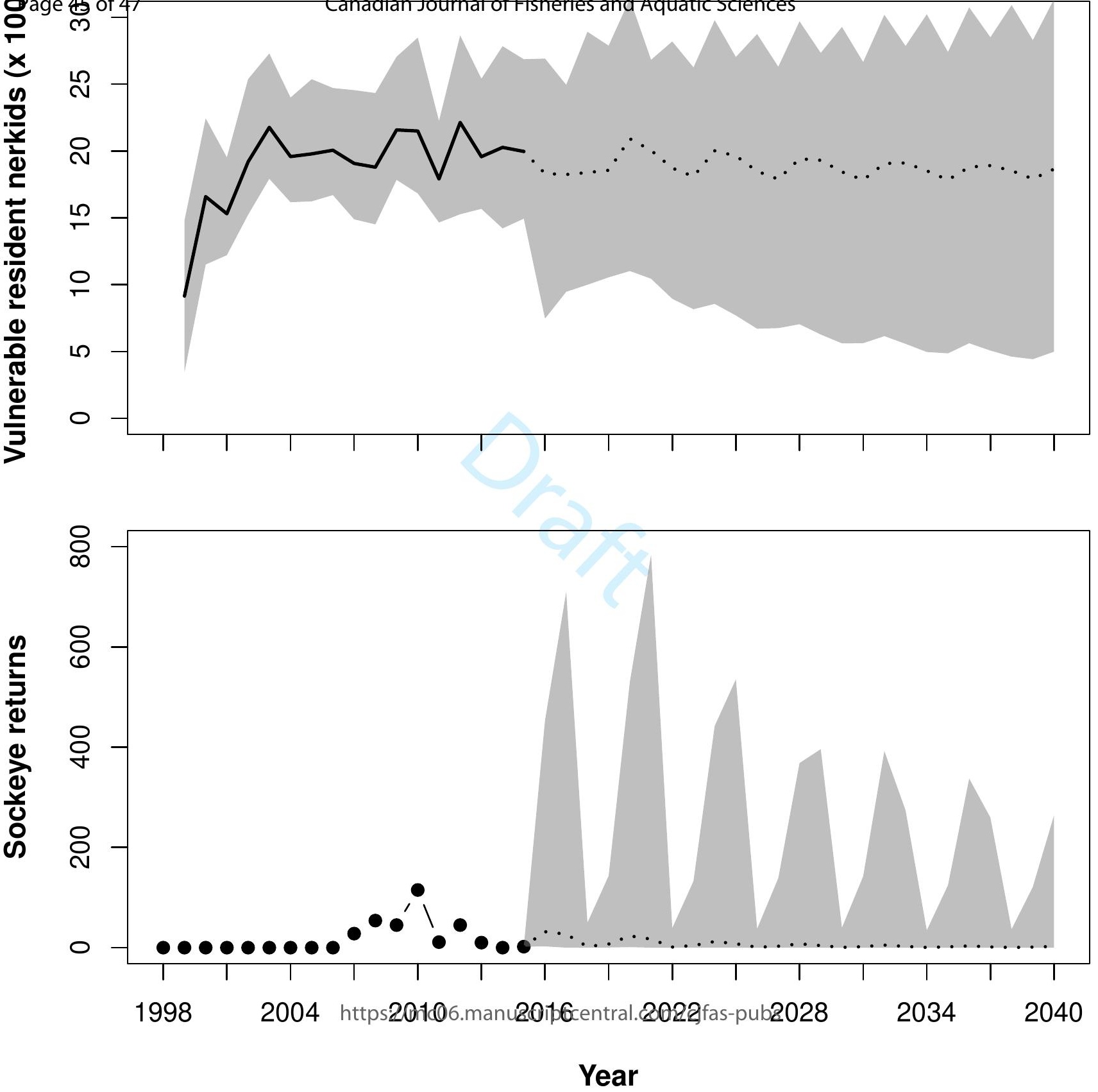

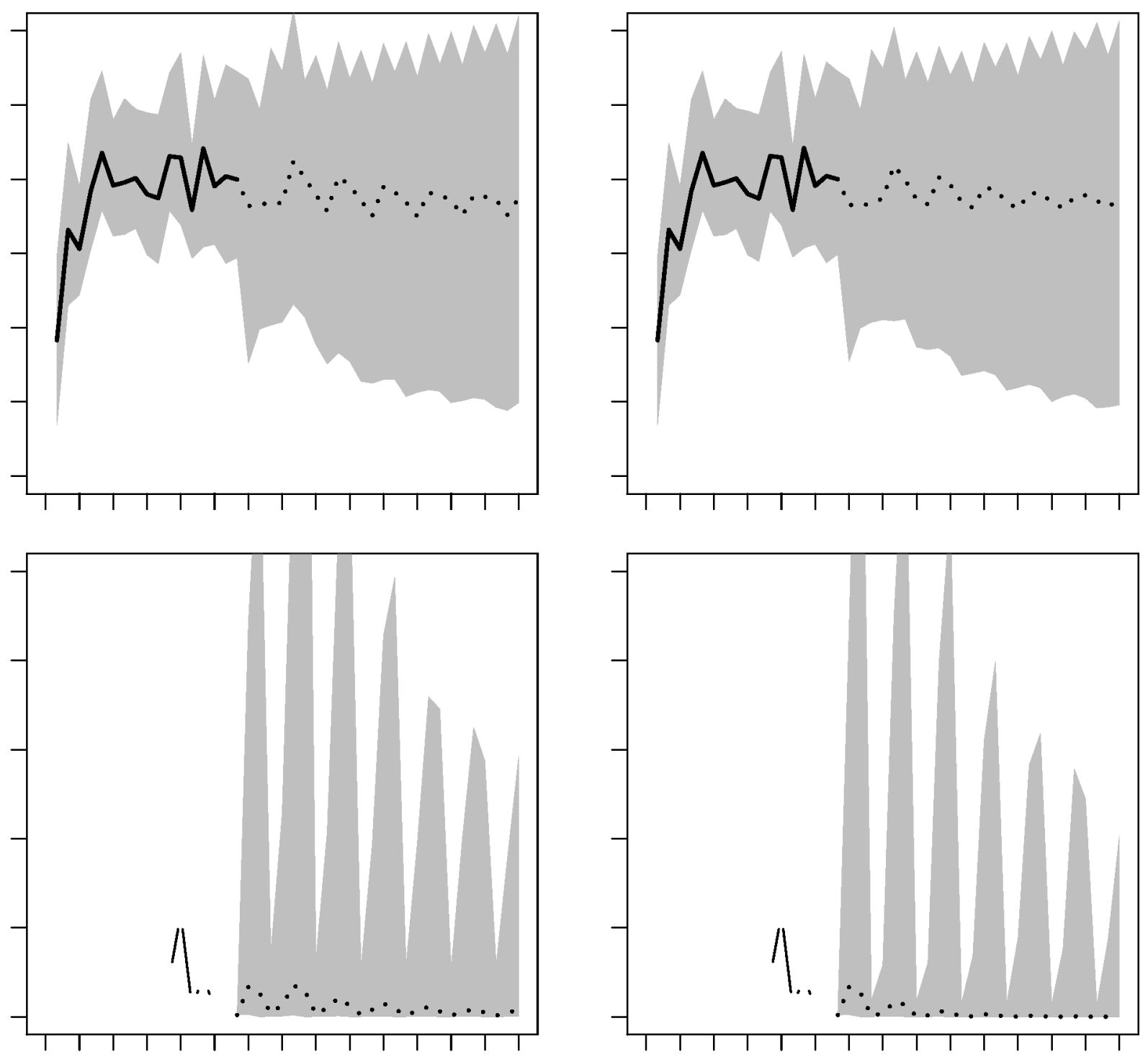
